ORIGINAL ARTICLE

\title{
Temporomandibular Disorders among Adolescents of Haryana, India: A Cross-sectional Study
}

\author{
Pratibha Taneja ${ }^{1}$, Ruchi Nagpal ${ }^{2}$, Charu M Marya ${ }^{3}$, Sakshi Kataria ${ }^{4}$, Vibhav Sahay ${ }^{5}$, Deepak Goyal ${ }^{6}$
}

\begin{abstract}
Aim: The aim of the present study was to determine the prevalence and determinants of temporomandibular disorders (TMD) among 12- to 15-year-old adolescents of Faridabad.

Materials and methods: The study included a sample of 300 adolescents (132 males and 168 females) with age ranging from 12 to 15 years. Data were collected through clinical examination and Fonseca anamnestic questionnaire. The prevalence of TMD signs was assessed through Fonseca anamnestic questionnaire while TMD symptoms were measured by clinical examination. Various determinants of TMDs such as Angle's classification, crossbite, overjet, overbite were also recorded. Data were then analyzed using SPSS version 21. Inferential statistics were performed using Chi-square test.

Results: The overall prevalence of both TMD signs and symptoms was 51\%. Females had higher prevalence (57.1\%) of TMD symptoms when compared to males (43.2\%). TMD signs has shown a statistical significant relationship with overbite $(p=0.007)$ and bruxism $(p<0.0001)$ only. No significant association was found between age, gender, Angle's molar relation, crossbite, and TMD signs. Statistical significant association was found between gender $(p=0.016)$, Angle's molar relation $(p=0.005)$, overbite $(p=0.001)$, crossbite $(p=0.030)$, bruxism $(p<0.0001)$, and TMD symptoms.
\end{abstract}

Conclusion: No Significant relationship was reported between malocclusions and TMD sign except for overbite and bruxism, but significant relationship were found between TMD symptoms and malocclusion.

Keywords: Temporomandibular disorders, Temporomandibular disorders signs, Temporomandibular disorders symptoms.

International Journal of Clinical Pediatric Dentistry (2019): 10.5005/jp-journals-10005-1689

\section{INTRODUCTION}

The ability to talk freely and chew openly without any restrictions is all due to the presence of a hingejoint on the either side of the face known as the temporomandibular joint (TMJ). It is made up of complex structures such as joints, tissues, muscles, and vessels. 'It connects the lower jaw to the temporal bone of the skull, which is immediately in front of the ears on each side on the head. ${ }^{2}$ The presence of this joint allows the free movement of the jaw during mastication and speech. ${ }^{1}$ The presence of muscles that is attached to and surrounding the joint controls the position and movement of the jaw. ${ }^{3}$ Grinding or clenching, injury to the jaw, dislocation of the disks, and malocclusion are some of the many causes that contribute to the temporomandibular disorders (TMDs). ${ }^{4}$

Temporomandibular disorders have been identified as a major cause of orofacial pain of non-dental origin. ${ }^{5}$ The WHO has emphasized the importance of being free of chronic orofacial pain as a clear prerequisite for oral health, as well as the negative effect of functional problems, such as chewing and eating, on the individual's well-being and daily living, making them determinants of oral and general health. Individuals with TMD symptoms have been found to seek different care providers and utilize the healthcare system to a greater degree, as well as being more frequently on sick leave than subjects without these conditions. Patients with TMD consequently experience a considerable negative effect on their quality of life. ${ }^{6}$

Temporomandibular disorder is a very important disorder that is often discussed in dentistry. Temporomandibular disorder is defined as a collective term that enfolds a number of clinical problems that involves the masticatory muscles, the TMJ and the associated structures and forms a prevalent clinical entity afflicting the masticatory muscles. ${ }^{1}$ It is considered to be a musculoskeletal disorder as it also the main cause of pain of non-dental origin in \begin{tabular}{l}
\hline${ }^{1-4}$ Department of Public Health Dentistry, Sudha Rustagi College of \\
Dental Sciences and Research, Faridabad, Haryana, India \\
${ }^{5}$ Department of Orthodontics, Government Dental College and \\
Hospital, Jaipur, Rajasthan, India \\
${ }^{6}$ Department of Orthodontia and Dentofacial Orthopaedics, RUHS \\
College of Dental Sciences, Jaipur, Rajasthan, India \\
Corresponding Author: Pratibha Taneja, Department of Public \\
Health Dentistry, Sudha Rustagi College of Dental Sciences and \\
Research, Faridabad, Haryana, India, Phone: +91 9654642392, e-mail: \\
pratibhataneja3@gmail.com \\
How to cite this article: Taneja P, Nagpal R, Marya CM, et al. \\
Temporomandibular Disorders among Adolescents of Haryana, India: \\
A Cross-sectional Study. Int J Clin Pediatr Dent 2019;12(6):500-506. \\
Source of support: Nil \\
Conflict of interest: None \\
\hline \hline
\end{tabular}

the orofacial region including the head, face, and related structures. Although the etiology of the TMD is poorly understood and is said to be multifactorial, it is often concluded that malocclusion is the one of the main causes of the disorder, other causes being parafunctional habits and hyperlaxity of the joint. ${ }^{7}$

Temporomandibular disorders occur as a result of problems to the jaw, jaw joint, and surrounding facial muscles that control chewing and moving the jaw. ${ }^{8}$ Among all of these factors, occlusion is most often cited as one of the major etiological factors causing TMDs. Several theories are based on the presumption that there is an association between and have justified the use of occlusal appliance therapy, anterior repositioning appliances, occlusal adjustments, and orthodontic and orthognathic treatment. ${ }^{8}$ 
The symptoms commonly related to TMD are pain from the face and jaw area at rest or on function, jaw tiredness, TMJ sounds such as clicking or crepitation, jaw movement limitations, and locking/catching or luxation of the mandible. ${ }^{9}$ The signs regarded as clinical indicators of TMD are tenderness upon palpation of the TMJs and the masticatory muscles, TMJ sounds and irregular paths of jaw movement, impaired jaw movement capacity, and pain on jaw movement. ${ }^{10}$

Reported prevalence rates vary broadly among adolescents (from 26 to 50\%) reflecting important differences in sample, criteria, and methods used for collecting information. ${ }^{11}$ Due to high prevalence and variability of complaints, TMD is diagnosed by associating signs and symptoms as some characteristics may be frequent even in a nonaffected population. Different questions covering major TMD signs and symptoms have been collaborated to simplify the evolution in epidemiologic studies and to standardize research samples. ${ }^{12}$

The literature lacks studies with respect to the prevalence of TMD signs and symptoms in subjects with different dental characteristics (Angle's dental classes and presence of crossbite) among adolescents, especially Indian population. Hence, this study was conducted to assess the prevalence and determinants of TMD among 12 years to 15 -years-old adolescents of Faridabad.

\section{Materials and Methods}

A cross-sectional epidemiological study was carried out to assess the prevalence and determinants of TMD among adolescents of Faridabad. The study population was selected from various secondary schools of Faridabad. Ethical clearance was sought from the institutional ethical committee, after explaining the aim and importance of the study. Informed consent was obtained from each subject's parent, and assent was taken from each subject him/herself prior to clinical examination. The subjects aged between 12 years and 15 years who brought the parental/guardian consent and who wanted to participate and present on the day of the examination were included in the study. The patients with history of polyarthritis, acute traumatic injury, metabolic diseases, neurological disorders, vascular disease, neoplasia, psychiatric disorders, motor vehicle accidents, or presented with visual, auditory, or motor impairments or any congenital abnormalities in relation to TMJ were excluded from the study.

\section{Sample Size Calculation}

A pilot study was conducted to check the feasibility of the methodology planned and for sample size estimation. The sample size was determined by the following formula:

$$
N=Z^{2}\{P(1-P)\} / e^{2}
$$

Using the prevalence of $25 \%$ obtained through a pilot study, the final estimated sample size required for the study was 296, which was rounded off to 300 in order to obtain a $95 \%$ confidence interval level and at least $80 \%$ power of analysis with $5 \%$ of absolute error.

A stratified two-stage cluster sampling technique with schools as primary sampling unit was utilized to obtain the required sample size of 300 students from secondary schools of Faridabad. According to administrative structure, Faridabad city is divided into two blocks, that is, Faridabad block and Ballabhgarh block. At the first stage of sampling, out of two blocks, Faridabad block was chosen randomly. For the second stage, "school" was decided as the sampling unit. So, the complete list of secondary and senior secondary schools was obtained from district educational office. Cluster size was predefined as 50 students per school. Now, to achieve the sample size of 300 students $(300 / 50=6)$, six schools were required. To obtain six secondary schools from Faridabad block, lottery method was used. To substitute for the refusal to participation and incomplete questionnaires, one extraschool was also selected.

\section{Reliability and Validity of Data}

The clinical examination of all the subjects was done by a single examiner. The examiner was trained under the guidance of a professional having previous experience in conducting such surveys to limit the intraexaminer variability. The training continued till the examiner started producing consistent observations to limit the intra-examiner variability. The intraexaminer reliability was checked by performing repeat examination on $10 \%$ randomly selected subjects and the intraexaminer $\kappa$ coefficient values for various occlusal parameters were calculated to be $\geq 0.79$.

\section{Data Collection}

Data were collected using a combination of structured questionnaire (self-administered) and clinical examination.

\section{Questionnaire}

Questionnaire consisted of two sections. The first section was comprised of questions regarding subject's sociodemographic variables such as age, gender address, and school name. The second section consisted of Fonseca's anamnestic questionnaire aimed at detecting the presence and severity of TMD. An anamnestic Fonseca's questionnaire was used to record the TMD symptoms. ${ }^{13}$ It is composed of 10 questions regarding TMD symptom, which includes checking for the presence of difficulty while opening mouth, difficulty in lateral jaw movements, muscle pain while chewing, headaches, neck pain, pain in TMJ, ear, or shoulder, and emotional stress. All the descriptions or complaints by the subjects were considered as symptoms. The subjects were informed that these 10 questions could only be answered with "yes," "no," and "sometimes" and that only one answer should be marked for each question. A score of 0,5 , and 10 was given for corresponding responses of "no", "sometimes," and "yes," respectively. Score was then added for individuals. The sum of the values obtained provides an index that classifies individuals into the category of absence of TMD (0-15), mild (20-45), moderate (50-65), and severe TMD (70-100). There was no time limit for completion. That way, there would be no reasons for the subjects to give induced answers.

An American Dental Association type III clinical examination was conducted for all included subjects for the assessment of various TMD signs, that is, deviation during opening, reduced opening, lateral and protrusive movements, and myofacial pain. Angle's molar classification, crossbite, overjet, overbite, open bite, and bruxism were also recorded. The examination for TMD sign was based on the Standardized Research Diagnostic Criteria for TMDs.

\section{Data Analysis}

Data were analyzed by Statistical Package for Social Sciences (SPSS) version 21, IBM Inc. It was subjected to descriptive statistics for calculation of mean, standard deviation, frequencies, and percentages. Chi-square test was used for comparison between categorical variables. The level of statistical significance was set at $p$ value less than or equal to 0.05 . 


\section{Results}

\section{Demographic Details}

Study population comprised of 300, 12-15-year-old adolescents of Faridabad state was included in the study. Out of which, 132 (44\%) were males and 168 (56\%) were females. The number of males and females subjects did not vary significantly among different age groups $(p>0.05)$ (Table 1).

Out of total subjects examined, 29 (9.7\%) were free from any TMD symptoms, 213 (71\%) were having mild TMD, 41 (13.7\%) were having moderate TMD, and 16 (5.3\%) were having severe TMD symptoms. Overall, 202 (67.3\%) did not report any TMD sign(s), whereas 98 (32.7\%) were having TMD sign(s), that is, overall prevalence of TMD sign(s) was found to be $32.7 \%$.

The study found that 29 (9.7\%) subjects were not having any TMD symptoms, 213 (71\%) were having mild TMD, 41 (13.7\%) were having moderate TMD, and 16 (5.3\%) were having severe TMD symptoms (Table 2). The prevalence of TMD sign(s) was found to be significantly high among females compared with males. Among this study population, 6 (2\%) were having only TMD sign(s), 179 (59.7\%) were having only TMD symptoms, 92 (30.7\%) were having both sign(s) and symptoms, and 23 (7.7\%) were free from any TMD sign(s) or symptom (Table 3).

Only the presence of Bruxism was found to be significantly associated with TMD symptoms (Table 4). Table 5 shows that TMD sign was significantly associated with different categories of overbite, overjet, and presence or absence of bruxism only. The presence of TMD sign(s) was significantly associated with only

Table 1: Gender-wise distribution of subjects among different age groups

\begin{tabular}{lllll}
\hline & & \multicolumn{3}{c}{ Gender } \\
\cline { 3 - 5 } Age & & Male & Female & Total \\
\hline 12 years & $N$ & 39 & 36 & 75 \\
& $\%$ & $52.0 \%$ & $48.0 \%$ & $100.0 \%$ \\
13 years & $N$ & 38 & 49 & 87 \\
& $\%$ & $43.7 \%$ & $56.3 \%$ & $100.0 \%$ \\
14 years & $N$ & 29 & 40 & 69 \\
& $\%$ & $42.0 \%$ & $58.0 \%$ & $100.0 \%$ \\
15 years & $N$ & 26 & 43 & 69 \\
& $\%$ & $37.7 \%$ & $62.3 \%$ & $100.0 \%$ \\
Total & $N$ & 132 & 168 & 300 \\
& $\%$ & $44.0 \%$ & $56.0 \%$ & $100.0 \%$ \\
a $p$ value & & $0.365, \mathrm{NS}$ & & \\
\hline
\end{tabular}

${ }^{\mathrm{a} C h i-s q u a r e ~ t e s t . ~ N S, ~ n o t ~ s i g n i f i c a n t ~}$ bruxism: with an odds ratio of 5.87 but not with any other factors of functional occlusion (Table 6). Subjects with bruxism more frequently displayed more than one clinical sign of TMD than did those without bruxism

\section{Discussion}

The present research was focused to find the prevalence of TMD sign and symptoms among 12 years to 15 -year-old adolescents of Faridabad with the help of clinical examination and Fonseca anamnestic questionnaire. The Fonseca anamnestic index, which is used to measure TMD degree, provides a substantial amount of information in a short period of time and was considered sensitive and useful for identifying the TMD degree by other researchers. ${ }^{6}$

In the present study, there were no age differences regarding presence of sign(s) or symptom(s) of TMD or the examined baseline variables in the different age groups. The only discrepancy was a higher number of females in the younger part.

The prevalence of TMD in children and adolescents is difficult to establish. In this study, overall prevalence of TMD sign(s) was $32.7 \%$ whereas the prevalence of TMD sign(s) among males was found to be $25.8 \%$ and females was found to be $38.1 \%$. This finding is in the accordance with the study conducted by LeResche, ${ }^{14}$ De Oliveria et al., ${ }^{15}$ and Hirsch et al. ${ }^{16}$ in which they have also found a higher prevalence of TMD sign with respect to female gender. The reason for the gender differences is unknown, but the hormonal differences have been suggested as a causal factor. ${ }^{16}$

When TMD symptoms were categorized into mild, moderate, and severe based on Fonseca scoring, it was found that majority of the subjects were having mild TMD (71\%) followed by moderate (13.7\%), which is in accordance with the study conducted by Bagis et al., ${ }^{17}$ Dekon et al., ${ }^{18}$ Pedroni et al., ${ }^{19}$ De Oliveria, ${ }^{15}$ and Bonjardim et al. ${ }^{20}$

Mild TMD symptom was found among $71.3 \%$ subjects, whereas percentage of subjects suffering from moderate and severe TMD was found to be $13.7 \%$ and $5.3 \%$, respectively. The prevalence of mild and severe TMD symptom was found to be higher among females when compared to males. This finding corroborates with the study conducted by Syed et al., ${ }^{21}$ Minghelli et al., ${ }^{22}$ Agerberg, Inkapoo, and Kuttila et al. ${ }^{23}$ where TMD symptoms also were found to be more among females. According to the results of this study, there is a greater probability of finding some degree of TMD severity in female subjects than in males. According to Roda et al., ${ }^{24}$ these differences had been explained by behavioral, psychological, hormonal, and constitutional factors, but no conclusion had been drawn so far.

When we compared moderate to severe TMD degree for male and female subjects, the values of present study were higher as compared to the study done by Conti et al., ${ }^{25}$ which revealed that

Table 2: Distribution of study population according to the presence of temporomamdibular disorder (TMD) symptom(s) and sign(s) (one or more)

\begin{tabular}{|c|c|c|c|c|c|c|c|}
\hline \multirow[b]{2}{*}{ TMD symptom } & \multicolumn{2}{|c|}{ Males } & \multicolumn{2}{|c|}{ Females } & \multicolumn{2}{|c|}{ Total } & \multirow[b]{2}{*}{$p$ value } \\
\hline & $N$ & $\%$ & $N$ & $\%$ & $N$ & $\%$ & \\
\hline No TMD & 13 & 9.8 & 16 & 9.5 & 29 & 9.7 & $0.946, \mathrm{NS}$ \\
\hline Mild & 94 & 71.2 & 120 & 71.4 & 213 & 71.3 & \\
\hline Moderate & 19 & 14.4 & 22 & 13.1 & 41 & 13.7 & \\
\hline Severe & 6 & $4.5 \%$ & 10 & $6.0 \%$ & 16 & 5.3 & \\
\hline \multicolumn{8}{|l|}{ TMD sign(s) } \\
\hline Absent & 98 & 74.2 & 104 & 61.9 & 202 & 67.3 & $0.024^{*}$ \\
\hline Present & 34 & 25.8 & 64 & 38.1 & 98 & 32.7 & \\
\hline
\end{tabular}

*Statistically significant difference. NS, not significant 
$10 \%$ of females had moderate-to-severe TMD and $2.6 \%$ of males with moderate-to-severe TMD. Wänman and Agerberg ${ }^{23}$ found $13 \%$ and $7 \%$ with moderate-to-severe TMD, and Rieder et al. ${ }^{26}$ found $10.3 \%$ with advance and severe TMD. This shows that although the prevalence was high the severity of the condition is very low. This was also in agreement with the study done by Nassif et al. ${ }^{27}$

When risk factors for TMD such as malocclusion (Angle's classes II and III, bimaxillary protrusion, and different classes on both sides) crossbite, bruxism, open bite, overjet, and overbite were correlated with TMD signs, it was found that TMD signs were significantly associated with only overjet, overbite, and bruxism, whereas Angle's molar relation, crossbite, and open bite did not show any association with TMD sign, which is in contrast with the study conducted by Jenni et al. ${ }^{28}$ and Mohlin et al. ${ }^{29}$ who found no association between any single malocclusion and the severity of clinical signs.

When risk factors for TMD such as angles molar relation, crossbite, bruxism, open bite, overjet, and overbite were correlated with TMD symptoms, it was found that only bruxism $(p<0.05)$ was significantly

Table 3: Prevalence of temporomandibular disorder (TMD) symptoms and sign(s) (one or more)

\begin{tabular}{lll}
\hline $\begin{array}{l}\text { Only TMD sign(s), only TMD symptom, } \\
\text { or both TMD sign(s) + symptom }\end{array}$ & $n$ & $\%$ \\
\hline Only TMD sign(s) & 6 & 2 \\
Only TMD symptom & 179 & 59.7 \\
TMD sign(s) + symptom & 92 & 30.7 \\
No TMD sign(s)/symptom & 23 & 7.6 \\
Total & 300 & 100 \\
\hline
\end{tabular}

associated with TMD symptoms, which is in corroboration with the study conducted by Mohlin et al. ${ }^{29}$ Bruxism is one of the mentioned risk factors for TMD development. Bruxism in adolescents can be a reaction to stress, since they have not learned how to cope with such psychosocial problems, and unconscious let the stress out as a physical response. Overjet and overbite were found to be significantly associated with TMD sign(s) but not the symptoms(s).

In this study, the prevalence of only TMD signs was $2 \%$, only TMD symptom(s) was 59.7 and prevalence for both sign(s) and symptom(s) was $30.7 \%$. In spite of a thorough literature search, no study could be found, which assessed the prevalence of only TMD sign and only TMD symptom or sign + symptom. An individual can have signs and symptoms of TMD without ever developing TMD, and the signs and symptoms can fluctuate over time. Our opinion is that the diagnosis manifest TMD should mean that you have TMD signs and symptoms, but more importantly you have TMD pain. So there arose a need to revalidate Fonseca questionnaire.

The influence of occlusal factors in the etiology of TMD is controversial. When analyzing adolescents of Faridabad, we did not find a relationship between different occlusion types and TMDs.

This was in agreement with the findings of the study conducted by Mohlin et al. ${ }^{29}$ who found no association between any malocclusion category and the severity of clinical signs, and Jenni et al. ${ }^{28}$ who also did not find any significant connection between occlusal interferences and the degree of clinical dysfunction. But Gesch et al. ${ }^{30}$ in his study reported a weak association between malocclusion and the functional and clinical parameters of occlusion.

Table 4: Bivariate analysis of temporomandibular disorder (TMD) symptoms and risk factors

\begin{tabular}{|c|c|c|c|c|c|c|}
\hline & & \multicolumn{4}{|c|}{ TMD symptom } & \multirow[b]{2}{*}{$p$ value } \\
\hline & & No TMD & Mild TMD & Moderate TMD & Severe TMD & \\
\hline \multicolumn{7}{|c|}{ Open bite } \\
\hline \multirow[t]{2}{*}{ Absent } & $\mathrm{N}$ & 27 & 204 & 40 & 16 & $0.660, \mathrm{NS}$ \\
\hline & $\%$ & $9.4 \%$ & $71.1 \%$ & $13.9 \%$ & $5.6 \%$ & \\
\hline \multirow[t]{2}{*}{ Present } & $\mathrm{N}$ & 2 & 10 & 1 & 0 & \\
\hline & $\%$ & $15.4 \%$ & $76.9 \%$ & $7.7 \%$ & $0.0 \%$ & \\
\hline \multicolumn{7}{|l|}{ Bruxism } \\
\hline \multirow[t]{2}{*}{ Absent } & $\mathrm{N}$ & 14 & 158 & 22 & 6 & $<0.001^{*}$ \\
\hline & $\%$ & $7.0 \%$ & $79.0 \%$ & $11.0 \%$ & $3.0 \%$ & \\
\hline \multirow[t]{2}{*}{ Present } & $\mathrm{N}$ & 15 & 56 & 19 & 10 & \\
\hline & $\%$ & $15.0 \%$ & $56.0 \%$ & $19.0 \%$ & $10.0 \%$ & \\
\hline \multicolumn{7}{|l|}{ Overbite } \\
\hline \multirow[t]{2}{*}{$0-3 \mathrm{~mm}$} & $\mathrm{~N}$ & 29 & 203 & 36 & 14 & 0.278 NS \\
\hline & $\%$ & $10.3 \%$ & $72.0 \%$ & $12.8 \%$ & $5.0 \%$ & \\
\hline \multirow[t]{2}{*}{$4-6 \mathrm{~mm}$} & $\mathrm{~N}$ & 0 & 10 & 4 & 2 & \\
\hline & $\%$ & $0.0 \%$ & $62.5 \%$ & $25.0 \%$ & $12.5 \%$ & \\
\hline \multirow[t]{2}{*}{$>6 \mathrm{~mm}$} & $\mathrm{~N}$ & 0 & 1 & 1 & 0 & \\
\hline & $\%$ & $0.0 \%$ & $50.0 \%$ & $50.0 \%$ & $0.0 \%$ & \\
\hline \multicolumn{7}{|l|}{ Overjet } \\
\hline \multirow[t]{2}{*}{$0-3 \mathrm{~mm}$} & $\mathrm{~N}$ & 25 & 194 & 37 & 14 & $0.641, \mathrm{NS}$ \\
\hline & $\%$ & $9.3 \%$ & $71.9 \%$ & $13.7 \%$ & $5.2 \%$ & \\
\hline 4-6 mm & $\mathrm{N}$ & 4 & 13 & 3 & 2 & \\
\hline
\end{tabular}


Contd...

\begin{tabular}{|c|c|c|c|c|c|c|}
\hline & & \multicolumn{4}{|c|}{ TMD symptom } & \multirow[b]{2}{*}{$p$ value } \\
\hline & & No TMD & Mild TMD & Moderate TMD & Severe TMD & \\
\hline & $\%$ & $18.2 \%$ & $59.1 \%$ & $13.6 \%$ & $9.1 \%$ & \\
\hline \multirow[t]{2}{*}{$>6 \mathrm{~mm}$} & $\mathrm{~N}$ & 0 & 7 & 1 & 0 & \\
\hline & $\%$ & $0.0 \%$ & $87.5 \%$ & $12.5 \%$ & $0.0 \%$ & \\
\hline \multicolumn{7}{|l|}{ Molar relation } \\
\hline \multirow[t]{2}{*}{ Bilateral class I } & $\mathrm{N}$ & 21 & 165 & 28 & 9 & $0.388, \mathrm{NS}$ \\
\hline & $\%$ & $9.4 \%$ & $74.0 \%$ & $12.6 \%$ & $4.0 \%$ & \\
\hline \multirow[t]{2}{*}{ Bilateral class II div I } & $\mathrm{N}$ & 3 & 19 & 4 & 3 & \\
\hline & $\%$ & $10.3 \%$ & $65.5 \%$ & $13.8 \%$ & $10.3 \%$ & \\
\hline \multirow[t]{2}{*}{ Bilateral class II div II } & $\mathrm{N}$ & 0 & 3 & 0 & 0 & \\
\hline & $\%$ & $0.0 \%$ & $100.0 \%$ & $0.0 \%$ & $0.0 \%$ & \\
\hline \multirow[t]{2}{*}{ Bilateral class III } & $\mathrm{N}$ & 0 & 0 & 0 & 0 & \\
\hline & $\%$ & $0.0 \%$ & $0.0 \%$ & $0.0 \%$ & $0.0 \%$ & \\
\hline \multirow[t]{2}{*}{ Different classes on the both sides } & $\mathrm{N}$ & 5 & 27 & 8 & 4 & \\
\hline & $\%$ & $11.4 \%$ & $61.4 \%$ & $18.2 \%$ & $9.1 \%$ & \\
\hline \multirow[t]{2}{*}{ Bimaxillary protrusion } & $\mathrm{N}$ & 0 & 0 & 1 & 0 & \\
\hline & $\%$ & $0.0 \%$ & $0.0 \%$ & $100.0 \%$ & $0.0 \%$ & \\
\hline \multicolumn{7}{|l|}{ Cross bite } \\
\hline \multirow[t]{2}{*}{ Absence of crossbite } & $\mathrm{N}$ & 23 & 168 & 34 & 13 & 0.516, NS \\
\hline & $\%$ & $9.7 \%$ & $70.6 \%$ & $14.3 \%$ & $5.5 \%$ & \\
\hline \multirow[t]{2}{*}{ Presence of anterior crossbite } & $\mathrm{N}$ & 6 & 35 & 6 & 2 & \\
\hline & $\%$ & $12.2 \%$ & $71.4 \%$ & $12.2 \%$ & $4.1 \%$ & \\
\hline \multirow[t]{2}{*}{ Presence of posterior bilateral crossbite } & $\mathrm{N}$ & 0 & 2 & 1 & 1 & \\
\hline & $\%$ & $0.0 \%$ & $50.0 \%$ & $25.0 \%$ & $25.0 \%$ & \\
\hline \multirow[t]{2}{*}{ Presence of posterior unilateral crossbite } & $\mathrm{N}$ & 0 & 9 & 0 & 0 & \\
\hline & $\%$ & $0.0 \%$ & $100.0 \%$ & $0.0 \%$ & $0.0 \%$ & \\
\hline
\end{tabular}

Table 5: Relationship between temporomandibular disorder (TMD) sign(s) and risk factors

\begin{tabular}{|c|c|c|c|c|}
\hline & & \multicolumn{2}{|c|}{ TMD sign(s) } & \multirow[b]{2}{*}{$p$ value } \\
\hline & & Absent & Present & \\
\hline \multicolumn{5}{|l|}{ Overbite } \\
\hline \multirow[t]{2}{*}{$0-3 \mathrm{~mm}$} & $\mathrm{~N}$ & 195 & 87 & $0.014^{*}$ \\
\hline & $\%$ & $69.1 \%$ & $30.9 \%$ & \\
\hline \multirow[t]{2}{*}{$4-6 \mathrm{~mm}$} & $\mathrm{~N}$ & 7 & 9 & \\
\hline & $\%$ & $43.8 \%$ & $56.3 \%$ & \\
\hline \multirow[t]{2}{*}{$>6 \mathrm{~mm}$} & $\mathrm{~N}$ & 0 & 2 & \\
\hline & $\%$ & $0.0 \%$ & $100.0 \%$ & \\
\hline \multicolumn{5}{|l|}{ Overjet } \\
\hline \multirow[t]{2}{*}{$0-3 \mathrm{~mm}$} & $\mathrm{~N}$ & 184 & 86 & $0.013^{*}$ \\
\hline & $\%$ & $68.1 \%$ & $31.9 \%$ & \\
\hline \multirow[t]{2}{*}{$4-6 \mathrm{~mm}$} & $\mathrm{~N}$ & 10 & 12 & \\
\hline & $\%$ & $45.5 \%$ & $54.5 \%$ & \\
\hline \multirow[t]{2}{*}{$>6 \mathrm{~mm}$} & $\mathrm{~N}$ & 8 & 0 & \\
\hline & $\%$ & $100.0 \%$ & $0.0 \%$ & \\
\hline \multicolumn{5}{|l|}{ Bruxism } \\
\hline \multirow[t]{2}{*}{ Absent } & $\mathrm{N}$ & 147 & 53 & $0.001^{*}$ \\
\hline & $\%$ & $73.5 \%$ & $26.5 \%$ & \\
\hline Present & $\mathrm{N}$ & 55 & 45 & \\
\hline
\end{tabular}


Contd...

\begin{tabular}{|c|c|c|c|c|}
\hline & & \multicolumn{2}{|c|}{$T M D \operatorname{sign}(s)$} & \multirow[b]{2}{*}{$p$ value } \\
\hline & & Absent & Present & \\
\hline & $\%$ & $55.0 \%$ & $45.0 \%$ & \\
\hline \multicolumn{5}{|l|}{ Open bite } \\
\hline \multirow[t]{2}{*}{ Absent } & $\mathrm{N}$ & 193 & 94 & $0.88, \mathrm{NS}$ \\
\hline & $\%$ & $67.2 \%$ & $32.8 \%$ & \\
\hline \multirow[t]{2}{*}{ Present } & $\mathrm{N}$ & 9 & 4 & \\
\hline & $\%$ & $69.2 \%$ & $30.8 \%$ & \\
\hline \multicolumn{5}{|l|}{ Molar relation } \\
\hline \multirow[t]{2}{*}{ Bilateral class I } & $\mathrm{N}$ & 150 & 73 & $0.690, \mathrm{NS}$ \\
\hline & $\%$ & $67.3 \%$ & $32.7 \%$ & \\
\hline \multirow[t]{2}{*}{ Bilateral class II div I } & $\mathrm{N}$ & 20 & 9 & \\
\hline & $\%$ & $69.0 \%$ & $31.0 \%$ & \\
\hline \multirow[t]{2}{*}{ Bilateral class II div II } & $\mathrm{N}$ & 3 & 0 & \\
\hline & $\%$ & $100.0 \%$ & $0.0 \%$ & \\
\hline \multirow[t]{2}{*}{ Bilateral class III } & $\mathrm{N}$ & 0 & 0 & \\
\hline & $\%$ & $0.00 \%$ & $0.00 \%$ & \\
\hline \multirow[t]{2}{*}{ Different classes on the both side } & $\mathrm{N}$ & 28 & 16 & \\
\hline & $\%$ & $63.6 \%$ & $36.4 \%$ & \\
\hline \multirow[t]{2}{*}{ Bimaxillary protrusion } & $\mathrm{N}$ & 1 & 0 & \\
\hline & $\%$ & $100.0 \%$ & $0.0 \%$ & \\
\hline \multicolumn{5}{|l|}{ Cross bite } \\
\hline \multirow[t]{2}{*}{ Absence of crossbite } & $\mathrm{N}$ & 161 & 77 & $0.08, \mathrm{NS}$ \\
\hline & $\%$ & $67.6 \%$ & $32.4 \%$ & \\
\hline \multirow[t]{2}{*}{ Presence of anterior crossbite } & $\mathrm{N}$ & 37 & 12 & \\
\hline & $\%$ & $75.5 \%$ & $24.5 \%$ & \\
\hline \multirow[t]{2}{*}{ Presence of posterior bilateral crossbite } & $\mathrm{N}$ & 0 & 4 & \\
\hline & $\%$ & $0.0 \%$ & $100.0 \%$ & \\
\hline \multirow[t]{2}{*}{ Presence of posterior unilateral crossbite } & $\mathrm{N}$ & 4 & 5 & \\
\hline & $\%$ & $44.4 \%$ & $55.6 \%$ & \\
\hline
\end{tabular}

*Statistically significant difference. NS, not significant

Table 6: Multivariate logistic regression for association of temporomandibular disorder (TMD) signs and risk factors

\begin{tabular}{|c|c|c|c|c|c|c|}
\hline & \multirow[b]{2}{*}{ Wald } & \multirow[b]{2}{*}{$d f$} & \multirow[b]{2}{*}{ Sig. } & \multirow[b]{2}{*}{$\operatorname{Exp}(B)$} & \multicolumn{2}{|c|}{$95 \%$ Cl for $\operatorname{EXP}(B)$} \\
\hline & & & & & Lower & Upper \\
\hline Over bite & 0.000 & 1 & 0.998 & 64508824.197 & 0.000 & \\
\hline Overjet & 0.000 & 1 & 0.997 & 78127835.668 & 0.000 & \\
\hline Bruxism & 5.875 & 1 & 0.015 & 0.317 & 0.125 & 0.802 \\
\hline Open bite & 0.584 & 1 & 0.445 & 0.421 & 0.046 & 3.869 \\
\hline Deep bite & 0.000 & 1 & 0.998 & 132787429.197 & 0.000 & \\
\hline Angles & 2.144 & 4 & 0.709 & & & \\
\hline Angles (class I) & 0.000 & 1 & 1.000 & 0.000 & 0.000 & \\
\hline Angles (class II div 1) & 0.000 & 1 & 1.000 & 0.000 & 0.000 & \\
\hline Angles (class II div 2) & 0.000 & 1 & 1.000 & 0.674 & 0.000 & \\
\hline Angles (class III) & 0.000 & 1 & 1.000 & 0.000 & 0.000 & \\
\hline Constant & 0.000 & 1 & 1.000 & 1615480989.752 & & \\
\hline
\end{tabular}

Because of the different angulations in the articles and the large variations in the reported frequencies of TMD signs and symptoms, it is difficult to obtain a comprehensive picture of the actual prevalence of TMD in children and adolescents. The variation can be explained with the differences in the population investigated, but also which examination method and diagnostic criteria's that is used.

\section{Conclusion}

The following conclusions can be drawn on the basis of the present study:

The prevalence of TMD symptoms in our sample of 300 patients was high for women. According to Fonseca questionnaire, mild 
TMD degree was the most prevalent category for female and male patients. Bruxism was found to be the risk factor for both TMD sign(s) and symptom(s) but overjet and overbite was associated with only TMD sign(s). The reason why females constitute the majority of patients and the exact role of occlusion and psychological factors in contributing to TMD is still unknown. It seems equally important to suggest that further research is needed.

\section{References}

1. Chokalingam S, Felicita AS. Malocclusion and TMJ disease-a review of literature. OSR-JDMS 2014;13(1):71-73. DOI: 10.9790/0853-131107173.

2. Temporomandibular Joint (TMJ) Syndrome (Temporomandibular Joint Disorder). Available at: http://www.emedicinehealth.com/ temporomandibular_joint_tmj_syndrome/article_em.htm.

3. Overview of temporomandibular disorders (TMD). Available at: http://www.clevelandclinic.org/health/health-info/docs/4900/4959. asp?index $=15066$.

4. Clenching \& Grinding Bruxism. Available at: http://www.scident.ca/ scident/Clenching_\%26_Grinding.html.

5. Romero-Reyes M, Uyanik JM. Orofacial pain management: current perspectives. Journal of Pain Research 2014;7:99-115. DOI: 10.2147/ JPR.S37593.

6. Hamissi J. The Principles Prevention in Dentistry, Oral Health Care Pediatric, Research, Epidemiology and Clinical Practices Virdi Mandeep, ed., InTech; 2012. ISBN: 978-953-51-0133-8, available from: http://www.intechopen.com/books/oral-health-care-pediatricresearch-epidemiology and clinical practices/the principles prevention-in-dentistry.

7. Guidelines for the Diagnosis and Management of Disorders Involving the Temporomandibular Joint and Related Musculoskeletal Structures. American Society of Temporomandibular Joint Surgeons. http://www.astmjs.org/frame_guidelines.html.

8. Management of Temporomandibular Disorders, National Institute of Health, Technology Assessment Conference Statement, April 29-May 11996.

9. Kohler AA. On temporomandibular disorders Time trends, associated factors, treatment need and treatment outcome. Swedish Dental Journal 2012;227:8.

10. Meyer RA. The Temporomandibular Joint Examination. In Walker HK, Hall WD, Hurst JW, ed. Clinical Methods: The History, Physical, and Laboratory Examinations, 3rd ed. Boston: Butterworths; 1990. Available from https://www.ncbi.nlm.nih.gov/books/NBK271/.

11. Modi P, Shaikh SS, Munde A. A Cross Sectional Study of Prevalence of Temporomandibular Disorders in University Students. International Journal of Scientific and Research Publications 2012;2(9):1-3.

12. Dworkin SF, LeResche L. Research diagnostic criteria for temporomandibular disorders: review, criteria, examinations and specifications, critique. J Craniomandib Disord 1992;6(4):301-355.

13. Nomura K. Use of Fonseca's questionnaire to assess the prevalence and severity of temporomandibular disorders in Brazilian dental undergraduates. Braz Dent J 2007;18(2):163-167. DOI: 10.1590/S010364402007000200015.

14. LeResche L. Epidemiology of temporomandibular disorders: implications for the investigation of etiologic factors. Crit Rev Oral Biol Med 1997;8:291-305. DOI: 10.1177/10454411970080030401.
15. De Oliveria AS. Prevalence study of signs and symptoms of temporomandibular disorder in Brazilian college students. Braz Oral Res 2006;20(1):3-7. DOI: 10.1590/S1806-83242006000100002.

16. Hirsch C, Hoffmann J, Türp J. Are temporomandibular disorder symptoms and diagnoses associated with pubertal development in adolescents? An epidemiological study. J Orofac Orthop 2012;73(1): 6-8. DOI: 10.1007/s00056-011-0056-x.

17. Bagis B, Ayaz EA, Turgut $S$, et al. Gender difference in prevalence of signs and symptoms of temporomandibular joint disorders: a retrospective study on 243 consecutive patients. Int J Med Sci 2012;9(7):539-544. DOI: 10.7150/ijms.4474.

18. Dekon SFC, Fajardo RS, Zavanelli AC, et al. Estudo comparativo entre índice anamnético de DTM e inventário de ansiedade traço-estado (IDATE). JBA: J Bras Oclusão, ATM Dor Orofac 2002;2(7):224-227.

19. Pedroni CR, Oliveira AS, Guaratini MI. Prevalence study and symptoms of temporomandibular disorders in university students. J Oral Rehabil 2003;30(2):283-289. DOI: 10.1046/j.1365-2842.2003.01010.x.

20. Bonjardim LR, Gaviao MB, Pereira LJ, et al. Anxiety and depression in adolescents and their relationship with signs and symptoms of temporomandibular disorders. Int J Prosthodont 2005;18: 347-352.

21. Syed RA, Syeda AA, Katti G. Prevalence of temporomandibular joint disorder in outpatients at Albadar dental college and hospital. J Indian Aca Oral Med Radiol 2012;24:261-268. DOI: 10.5005/jp-journals10011-1310.

22. Minghelli B, Cardoso I, Porfírio M, et al. Prevalence of temporomandibular disorder in children and adolescents from public schools in southern Portugal. N Am J Med Sci 2014;6:126-132. DOI: $10.4103 / 1947-2714.128474$.

23. Agerberg G, Inkapöol I.Craniomandibular disorders in urban Swedish population. J Craniomandib Disord 1990;4(3):154-164.

24. Poveda Roda R, Bagan JV, Díaz Fernández JM, et al. Review of temporomandibular joint pathology. Part I: classification, epidemiology and risk factors. Med Oral Patol Oral Cir Bucal 2007;12(4):292-298.

25. Conti PCR, Ferreira PM, Pegoraro LF, et al. A cross sectional study of prevalence and etiology of signs and symptoms of temporomandibular disorders in high school and university students. J Orofac Pain 1996;10(3):254-262.

26. Rieder CE. Comparison of the efficacy of a questionnaire, oral history and clinical examination in detecting sign and symptom of occlusal and temporomandibular joint dysfunction. J Prosthet Dent 1977;38(4):433-440. DOI: 10.1016/0022-3913(77)90097-X.

27. Nassif NJ, Hilsen KL. Screening for temporomandibular disorders: history and clinical examination. J Am Dent Assoc 1992;1(1):42-46. DOI: 10.1111/j.1532-849X.1992.tb00426.x.

28. Jenni M, Schurch E, Geering AH. Symptoms of functional disorders in the masticatory system: an epidemiological study (German). Schweiz Monatsschr Zahnmed 1987;9:1357-1365.

29. Mohlin B, Axelsson S, Paulin G, et al. TMD in relation to malocclusion and orthodontic treatment. The Angle Orthodontist 2007;77(3): 542-548. DOI: 10.2319/0003-3219(2007)077[0542:TIRTMA]2.0.CO;2.

30. Geseh D, Bernhardt $O$, Kerbschus A. Association of malocclusion and functional occlusion with temporomandibular disorders in adults 20 years or olders. A systemic review of population based studies. Quintessence Int J 2004;35:211-221. 